\title{
Long-term variation of wave characteristics on the Kaetsu Coast, Japan
}

\author{
Chung Trinh NGUYEN¹, Masatoshi YUHI² \\ ${ }^{1}$ Graduate School of Natural Science and Technology, Kanazawa University \\ (Kakuma-Machi, Kanazawa, Ishikawa 920-1192, Japan) \\ E-mail: chungjapan@yahoo.com.vn \\ ${ }^{2}$ Member of JSCE, Professor, School of Environmental Design, Kanazawa University \\ (Kakuma-Machi, Kanazawa, Ishikawa 920-1192, Japan) \\ E-mail:yuhi@se.kanazawa-u.ac.jp
}

\begin{abstract}
Kaetsu Coast is located on the middle north coast of Japan. This area has been suffering from various problems, including the progress of severe coastal erosion, frequent occurrence of rip current accidents, reduction of coastal habitats, and others. In order to cope with these problems, physical understanding of long-term wave characteristics is essentially important as basic engineering information. Accordingly, this study examines the long-term wave data observed at the Kanazawa Port in duration 1971-2012 in order to clarify the long-term as well as the seasonal characteristics in significant wave properties. On the overall, the seasonal variation in wave height, period, and direction is shown to be significant. The monthly-mean wave height and period are correlated with 2nd order polynomials very well. For the long-term variation, the annually-mean significant wave height indicates no significant trend. On the contrary, the Lepage statistical test detected an abrupt increase in the annually-mean significant wave period around 1990. In relation to these changes, the long-term variation in monthly-mean wave characteristics shows that the wave slope becomes smaller in the last two decades. The Mann-Kendall statistical tests demonstrated that the monthly-mean wave height and period in July have significantly increased during the study period. Several attempts have been made to correlate these features with climate changes.
\end{abstract}

Key Words: Kaetsu Coast, Kanazawa Port, NOWPHAS dataset, long-term wave observation, seasonal variation

\section{INTRODUCTION}

Kaetsu Coast is located on the middle north coast of Japan (Fig.1). The coastline includes approximately $75 \mathrm{~km}$ alongshore stretch and has a general NNE-SW orientation. This area has been suffering from various problems. The coast has experienced serious erosion for a long time under the combined influence of the persistent attack of high winter waves and human-related activities. On the northern area, the rip current accidents have frequently occurred in summer at the Uchinada district. Long-term reduction of coastal habitats is reported at Hakui area. For the time scale of several decades, the influence of climate change is also expected, that may cause further impacts on the coastal zone. In order to cope with these problems, physical understanding of long-term external forces is essentially important as basic engineering information.
Among the natural forces acting on Kaetsu Coast, the influence of wave action is considered to be dominant, because this area is micro tidal with maximum tidal range of $0.4 \mathrm{~m}$. Accordingly, this study investigates the long-term variation in wave characteristics for the last four decades observed at Kanazawa Port, which is located in the middle of the coast. First, the monthly-mean wave properties averaged over the observation period are examined in order to clarify the characteristics of seasonal variation. The correlation between the significant wave height and period are investigated. The long-term variations in annually- or monthly-mean wave properties are then examined on decadal time scales. Two kinds of statistical test are conducted in order to detect significant changes. For the typical changes in monthly-mean wave properties, comparisons have been made with several climate indices and incoming wave direction. 


\section{DATASETS AND METHODS}

\section{(1) Field site and datasets}

Kaetsu Coast is located on the middle north coast of the Japan Sea (Fig.1). At Kanazawa Port on the middle of the coast, the wave characteristics have been measured since 1970 by the Nationwide Ocean Wave information network for Ports and Harbors (NOWPHAS) $^{1)}$. In this study, the wave data from January 1971 to December 2012 have been used. Since the record comprises of 42 years, it is considered to be sufficiently long for the inspection of long-term changes. Two types of instruments have been used for the measurements at the Kanazawa site: Ultrasonic-type wave gauge (USW) from January 1971 to July 2003 at the water depth of $20.2 \mathrm{~m}$, and Doppler-type wave directional meter (DWDM) from August 2003 until now at $21.1 \mathrm{~m}$ of water depth. In both periods, the water depth at the observation site has been relatively shallow.

The observation data includes mean, significant, and $1 / 10$ wave height and period. The measurement of wave direction started from 2004. Accordingly, the data length of wave direction is less than 10 years and is not sufficiently long for the analysis of long-term variation. The statistical data processing had been performed in time intervals of 2 hours from the start of observations until 2005. From 2006, the data processing has been conducted every 20 minutes. In this study, the time intervals of 2 hours are used. The total number of original data over 4 decades is 176,064. Among them, 27,174 missing data are included, which is $15.4 \%$ of the total data.

\section{(2) Method of analysis}

Preliminarily, the acquisition rate for each year as well as each month was computed as a ratio between the number of normal data and the total data. When the acquisition rate was less than $70 \%$, the relative year or month was omitted. In the analysis, wave heights were first converted into corresponding deep water values based on the linear wave (shoaling) theory. The monthly-mean properties were then computed for the significant wave height and period in order to examine the seasonal variation and relation between them in duration 1971-2012. The seasonal variation of incoming wave direction has been examined for 2004-2012. When appropriate, the whole year was divided into 4 seasons: spring: from March to May; summer: from June to August; autumn: from September to November and winter: from December to next February. The values of annually-mean, maximum, and top 1\% (quantified as the $99 \%$ quantile of wave height records) significant wave properties were also computed to investigate

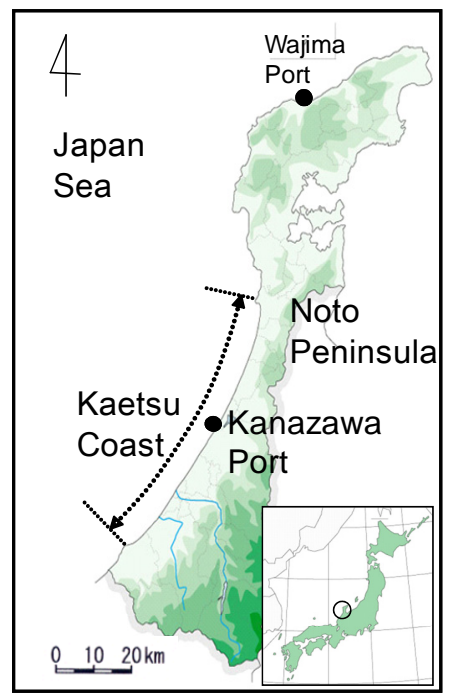

Fig.1 Location of research area

the long-term variation. The Mann-Kendall ${ }^{2)}$ and Lepage tests ${ }^{3)}$ have been conducted in order to detect the significant trend or jump in the long-term variation. Finally, typical long-term change in monthly-mean wave heights and periods was examined and compared with several climate indices and wave directions.

\section{SEASONAL VARIATION OF WAVE CHARACTERISTICS}

\section{(1) Wave heights and periods averaged over 1971 to 2012}

On the overall, the seasonal variation in wave characteristics is significant, which is known as a distinguishing feature of the Japan Sea coast ${ }^{4}$. Generally, wave conditions are really calm during summer. On the contrary, the wave climate becomes violent in the winter season due to the strong East Asian winter monsoon. In spring and autumn, waves are the medium.

Figures 2 show the seasonal variation in monthly-mean wave height and period, including the average, maximum, and minimum values in duration 1971-2012. The figures clearly illustrate that the wave heights and periods are the highest in winter, medium in spring and autumn and the lowest in summer. The mean heights of significant wave in summer are around $0.5 \mathrm{~m}$, while they are greater than approximately $2 \mathrm{~m}$ in winter: the significant wave height in winter is approximately 4 times larger than in summer. In spring and autumn season, wave height is in the range 0.5 to $1.5 \mathrm{~m}$.

The seasonal variation of wave period is quite similar to wave height variation. The significant waves in winter have longer period and the mean values are around $7 \mathrm{~s}$, while waves in summer have smaller period around $4.5 \mathrm{~s}$. The significant wave 


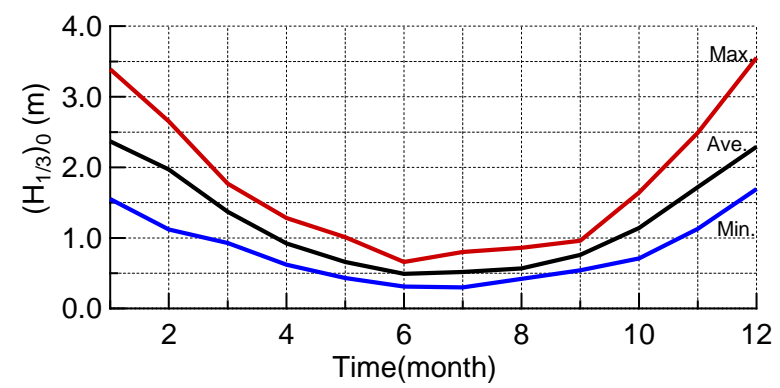

(a) Wave height

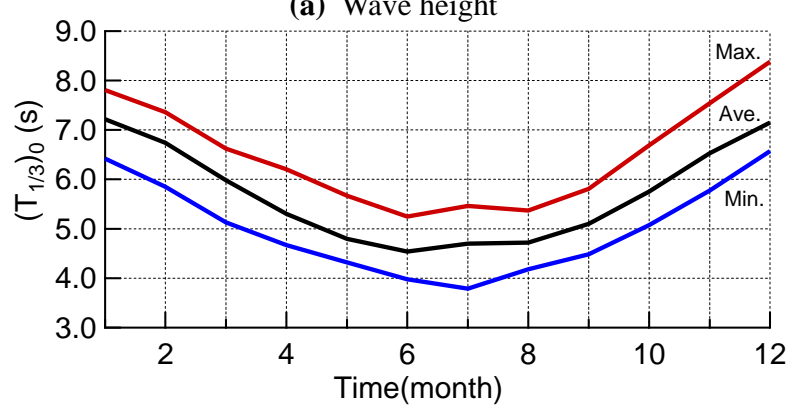

(b) Wave period

Fig.2 Seasonal variation in Monthly-mean wave properties

periods in winter are around 1.5 times those of the summer. In spring and autumn, the wave period is in the range 4.5 to $6.5 \mathrm{~s}$. On July, the curve for average values is slightly distorted. This is related to the long-term change, which will be discussed later.

The maximum and minimum values of monthly-mean wave height and period indicate essentially the same patterns of variation. The strength of year-to-year variation in the same month can be inspected from the range of the data, which is defined as the difference between the maximum and minimum values. The figures clearly show that the range of wave height becomes larger in winter and smaller in summer, while the seasonal variation in the data range of wave period is weak.

Figures 3 show the relationship between the monthly-averaged significant wave height and period, for (a) the average and (b) the maximum values during the observation period. In the figure, the regression results and several curves corresponding to typical wave slope $\left(H_{0} / L_{0}\right)$ are also included.

It is clearly shown in Fig. 3(a) that the mean values of wave height and period are strongly interdependent. They can be correlated very well with the following $2^{\text {nd }}$ order polynomial with the correlation coefficient of $\mathrm{R}^{2}=0.998$ :

$$
H_{1 / 3}=0.089 T_{1 / 3}^{2}-0.35 T_{1 / 3}+0.25
$$

Waves in winter are steeper than in summer. For the mean values, the wave slope in summer is asymptotic to 0.016 , while wave slope in winter becomes steeper (approximately 0.028).

Similarly, the maximum values of monthly-mean

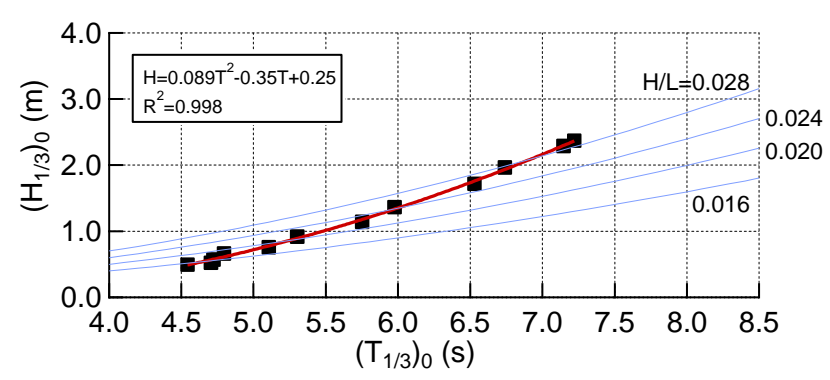

(a) Average height and period

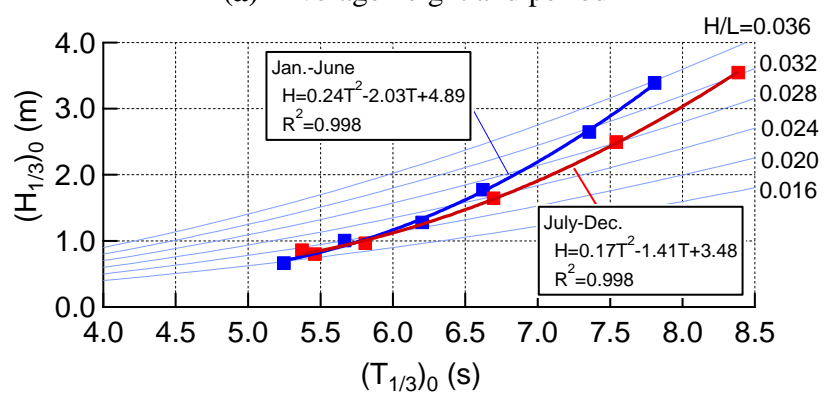

(b) Maximum height and period

Fig.3 Relationship between monthly-mean wave characteristics during 1971-2012

wave height and period are closely correlated (Fig.3(b)), but the resulting curves are slightly different for January-June and July-December duration.

$$
\begin{aligned}
& H_{1 / 3}=0.24 T_{1 / 3}{ }^{2}-2.03 T_{1 / 3}+4.89 \\
& \quad \text { (from January to June) } \\
& H_{1 / 3}=0.17 T_{1 / 3}{ }^{2}-1.41 T_{1 / 3}+3.48
\end{aligned}
$$$$
\text { (from July to December) }
$$

The correlation coefficients are $\mathrm{R}^{2}=0.998$ for both cases. The corresponding range of wave slope is from 0.016 to 0.036 , which is wider than that of the average values. Interestingly, with the same value of wave period, wave slope in duration of January to June is steeper than in July to December.

\section{(2) Wave direction from 2004 to 2012}

Figure 4 shows the incoming wave direction relating to wave period in January, April, July, and October that are representative for winter, spring, summer, and autumn season, respectively. In general, waves in winter have longer wave period and approach the coast mainly from the NNW direction. In spring, dominant wave direction is still the NNW but incoming wave direction spreads out toward the West. In addition, the number of waves with long period decreases. In summer, waves approach the coast mainly from both the NNW and NWW direction. The wave periods are the shortest. In autumn, incoming waves are again mainly from the NNW directions. The wave period in autumn is longer than that of summer. 


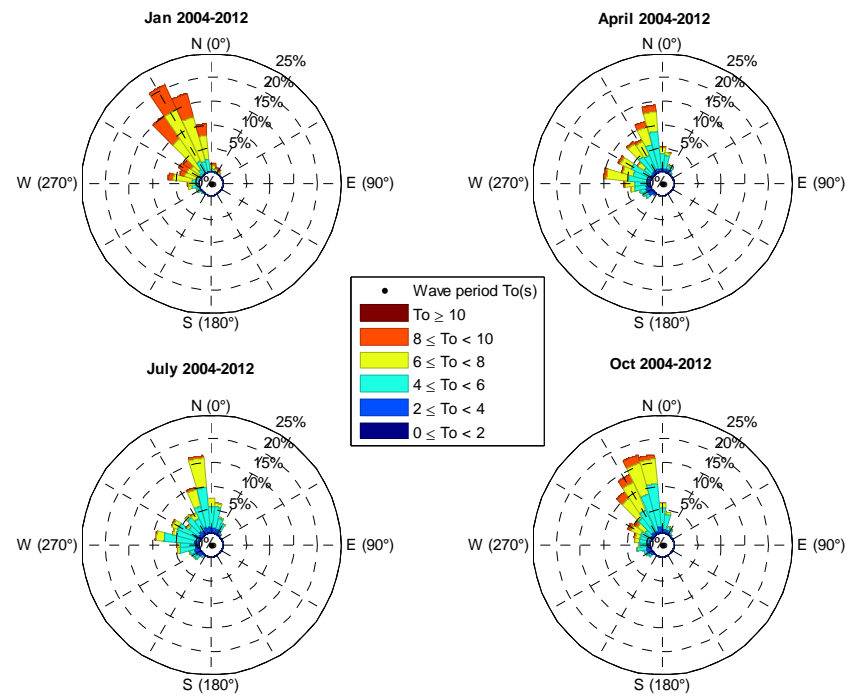

Fig.4 Incoming wave direction and wave periods in the 4 seasons

\section{LONG-TERM VARIATION OF WAVE CHARACTERISTICS}

\section{(1) Annually-mean wave characteristics}

Next, the long-term trends of variation in significant wave properties were analyzed in duration 1971-2012. Figure 5(a) shows the variation in annually-mean significant wave height. The figure illustrates that the significant wave height fluctuates between 1.00 and $1.36 \mathrm{~m}$. The statistical tests demonstrated that neither a trend nor a jump exists in the long-term variation. This is consistent with the analysis by Shimizu et al. (2006) ${ }^{5)}$ based on the observation around Japan over 35 years. A close inspection of Fig. 5(a) indicates that the data is more scattered recently: the standard deviation in the last 2 decades $(0.09 \mathrm{~m})$ has substantially increased compared with that in the first 2 decades $(0.06 \mathrm{~m})$.

According to Fig. 5(b), in contrast, the annually-mean significant wave period in the last 2 decades has noticeably increased to $5.8 \mathrm{~s}$ from the value in the former period (5.6 s). The Mann-Kendall test showed an increasing trend in wave period significant at the $1 \%$ level. The Lepage statistics with the sample size of 15 years also detected an abrupt jump in the annually-mean significant wave period around 1990 at the $1 \%$ significant level. This result is in agreement with the observation by Seki et al. (2012) ${ }^{6)}$ and Yamaguchi et al. (2007) ${ }^{7}$. The significant wave period fluctuates between 5.41 and $6.09 \mathrm{~s}$, and the standard deviations in the first 2 decades and last 2 decades have a noticeable discrepancy as well, in which the values are $0.11 \mathrm{~s}$ and $0.15 \mathrm{~s}$, respectively.

\section{(2) Episodic wave characteristics}

The maximum wave heights and periods fluctuate in a wide range. Figure 6(a) demonstrates that the maximum significant wave height reached up to

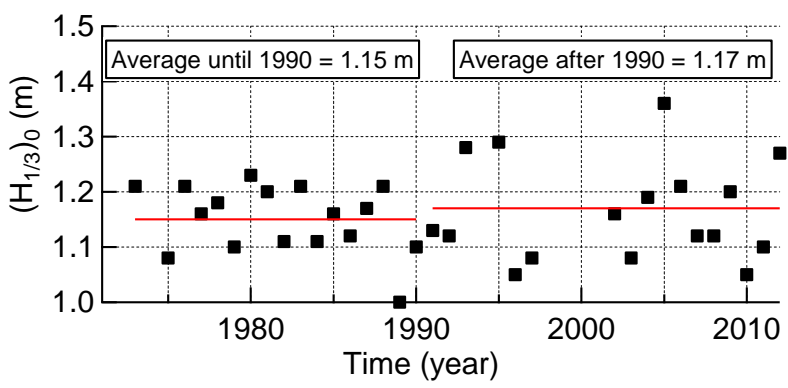

(a) Annually-mean wave height

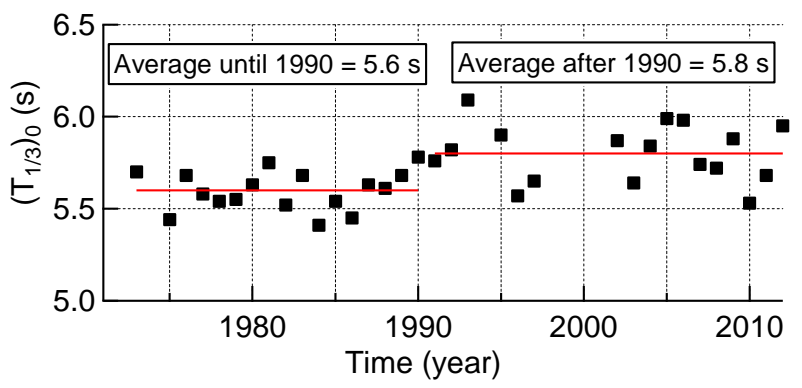

(b) Annually- mean wave period

Fig.5 Long-term variation in significant wave characteristics

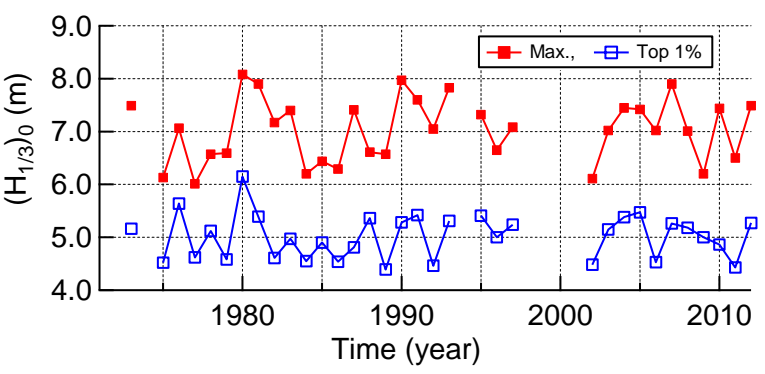

(a) Height of maximum and top $1 \%$ of waves

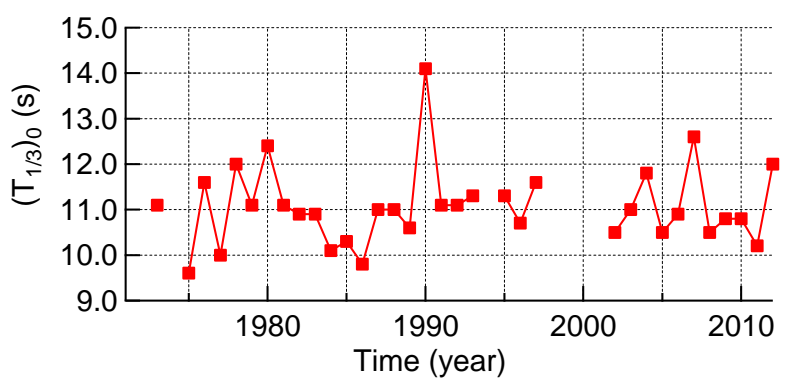

(b) Period of maximum significant waves

Fig.6 Long-term variation in episodic wave characteristics

$8.08 \mathrm{~m}$ at 1980 . In the same year, top $1 \%$ of significant wave height recorded the highest value of 6.15 m. In Fig. 6(b), it is shown that the maximum of the significant wave period was $14.1 \mathrm{~s}$ at 1990 . Mase et al. (2009) ${ }^{8)}$ mentioned the increasing tendency of maximum wave height around this site. As far as maximum and top $1 \%$ values are concerned, however, the statistics indicated no significant changes.

\section{(3) Monthly-mean wave characteristics}

Finally, the long-term variation in monthly-mean wave height and period were examined. Figures 7 show the relationship between the monthlymean significant wave height and period, which are 


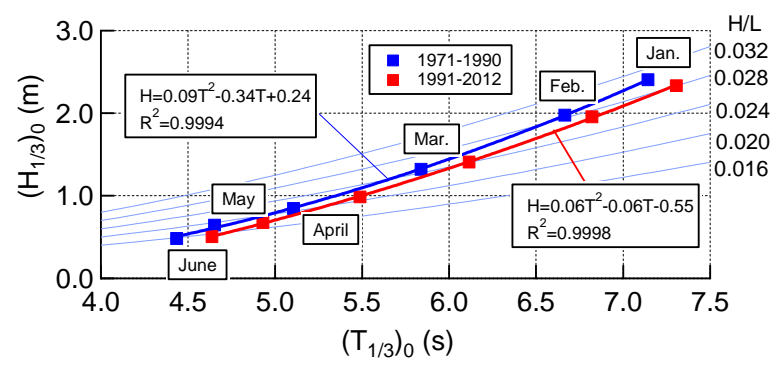

(a) From January to June

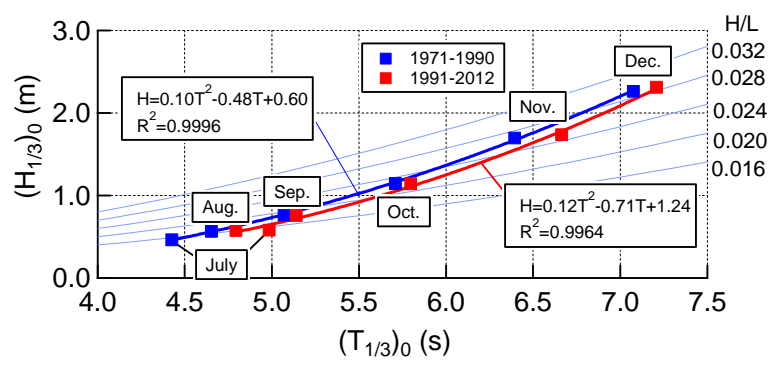

(b) From July to December

Fig.7 Comparison of the relationship between monthly-mean wave characteristics over two periods

averaged over in 2 different durations: from 1971 to 1990 and from 1991 to 2012. The variation of wave heights between the first 2 decades and the last 2 decades are not significant in general. In contrast, wave periods in the last 2 decades are always greater than that in the first 2 decades. In particular, the wave periods in July have significantly increased from $4.43 \mathrm{~s}$ in the first 2 decades to $4.98 \mathrm{~s}$ in the last 2 decades.

In order to detect the increasing/decreasing trend in monthly-mean wave height and period, the Mann-Kendall statistic tests have been conducted. For the wave height, the statistics indicated an increasing trend of the 5\% significance level in April and July. The Mann-Kendall statistics also demonstrated that the wave period in March, April and July have increasing trends significant at the $1 \%$ level. The wave period in May also has an increasing trend at the $5 \%$ level. The variations in typical months, where significant trend has been detected, are shown in Figs.8. A remarkable increasing tendency of wave period in July is recognized. Around the study area, previous related studies have pointed out the existence of an increasing trend in wave period during spring $^{6)}$ and summer ${ }^{6,7)}$. The present results are consistent with these observations. Moreover the results obtained in the present study clarified that the change in spring are commonly seen from March to May, but the change in summer is concentrated in July.

In order to obtain a further understanding on this distinguishing feature, wave characteristics in July of Wajima Port, which is $90 \mathrm{~km}$ northward from Kanazawa Port (Fig.1), were investigated. At Wajima,
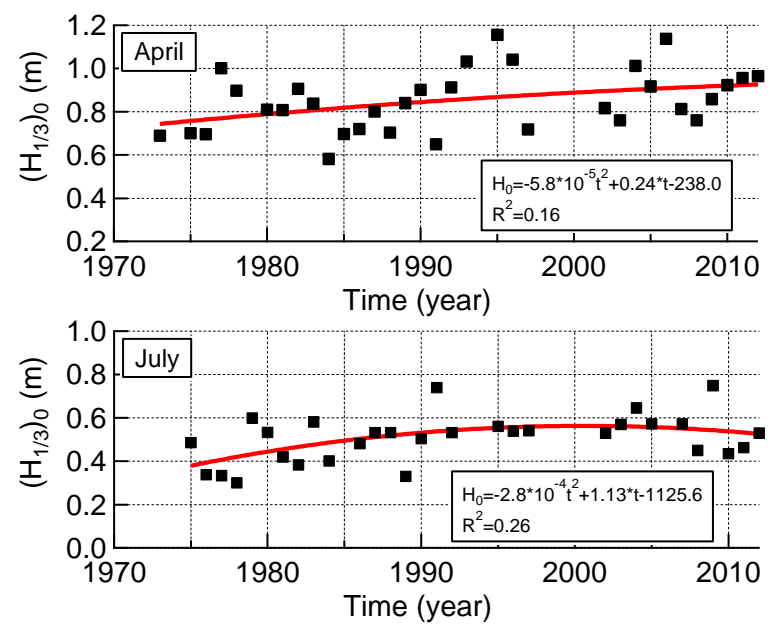

(a) Wave height
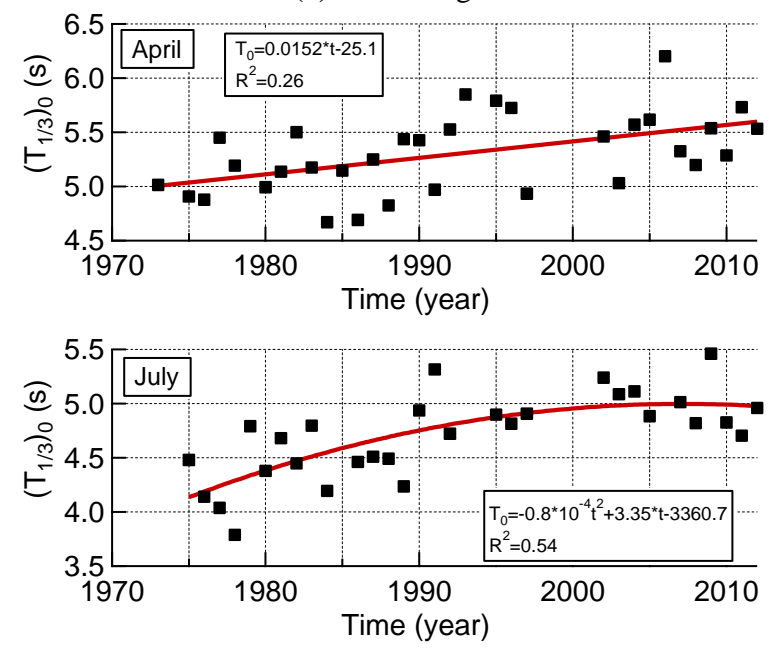

(b) Wave period

Fig.8 Long-term variation of monthly-mean significant wave characteristics in April and July

wave data are available from 1979 to 2012 . The data have been examined separately by 2 different durations: 1979-1990 and 1991-2012. The results show similar features to Kanazawa site: the wave period in the second duration has an increasing trend in comparison with that in the first duration, while the tendency in wave height variation is not clear. In addition, the variation in wave period is also significant in July: The averaged value in $1979-1990$ is $4.69 \mathrm{~s}$, while it is 5.19s in 1991-2012.

Several attempts have been made in order to deduce the possible cause of the change. First, the year-to-year variation of wave period in July is compared with several climate indices, including the Arctic Oscillation (AO), El Nino-Southern Oscillation (ENSO), Western Pacific (WP), North Pacific Index (NPI), and Zonal Index (ZI). While other indices have little correlation, WP index expresses a light impact on this change. Figure 9 shows the relation between monthly-mean wave period in July and corresponding WP index. The WP index seems 


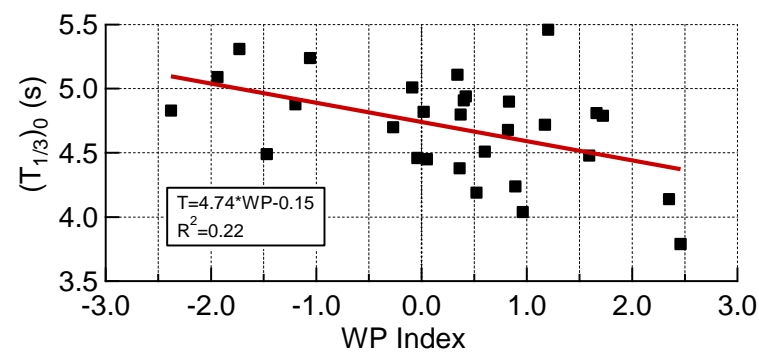

Fig.9 Relationship between monthly-mean wave period and Western Pacific index in July

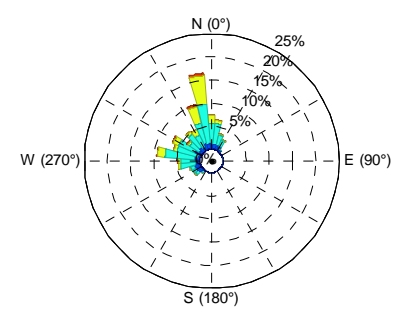

(a) Mean for 2004-2012

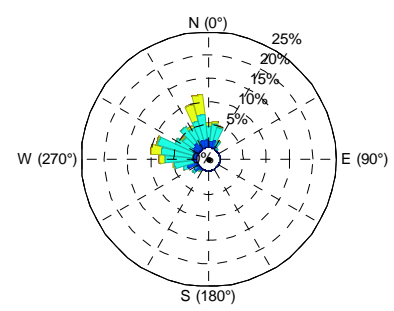

(c) 2011

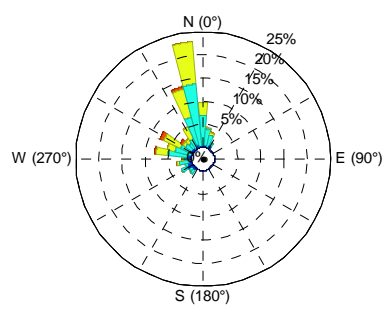

(b) 2009

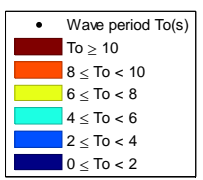

Fig.10 Wave direction relating to wave period in July

to have weak negative correlation with $\mathrm{R}^{2}=0.22$.

Next, the number of typhoons passing through the Japan Sea area in July has been examined. The number of typhoons increased in the duration 1991-2012, but the year-to-year change indicated little correlation with wave period variation. Furthermore, some correlation analyses are being conducted using the wind data in July based on JRA-55 (the Japanese 55-year Reanalysis) datasets provided by Japan Meteorological Agency. The preliminary results indicate, however, no clear tendency.

Finally, the influence of incoming wave direction is discussed based on the recent observation of wave direction. Figure 10 compares the distribution of incoming wave direction for the typical years when the wave period is long (2009) and short (2011). The averaged distribution over 2004-2012 is also included. The results imply that when the incoming waves from the NNW are quite dominant, the wave period becomes longer. On the contrary, when the waves from the NWW are equally important the wave period becomes short. The similar influence of wave direction change (the dominance of the NNW direction has been enhanced) could have occurred during the study period. However, numerical hindcasting is needed to examine it.

\section{SUMMARY REMARKS}

This study examined the long-term wave data observed at the Kanazawa Port in duration 1971-2012 in order to clarify the long-term as well as the seasonal characteristics in significant wave properties. On the overall, the seasonal variation in wave height, period, and direction were shown to be significant. The monthly-mean wave height and period were correlated with 2nd order polynomials very well. The annually-mean wave period indicated an abrupt increase around 1990. The increase of wave period was most significant in July.

Since the wave characteristics in July could have an impact on the occurrence of rip current accidents, it is important to understand the characteristics of these phenomena and to deduce the possible causes. Future projection is also desirable. For these purposes, more detailed analysis is needed based on the numerical simulation for the wind, wave and current field over the study area.

ACKNOWLEDGMENT: This study was partially supported by a Grant-in-Aid for Scientific Research by the Japan Society for the Promotion of Science (No. 25420517). The authors thank Dr. K. Taniguchi for the assistance in the JRA55 data analysis.

\section{REFERENCES}

1) Nagai, T., Sugahara, K., Hashimoto, N., Asai, T., Higashiyama, S., and Toda, K.: Introduction of Japanese NOWPHAS System and its Recent Topics, Proc. of the Int. Conf. on Hydro-Technical Eng. for Port and Harbor Construction (HYDRO-PORT'94), PHRI, pp.67-82, 1994.

2) Kendall, M. G.: A new measure of rank correlation, Biometrika, Vol.30, pp.81-93, 1938.

3) Lepage, Y.: A combination of Wilcoxon's and Ansari-Bradley's statistics, Biometrika, Vol.58, pp.212-217, 1971.

4) Kobune, K., Sugawara, K. and Goto, C.: Wave climate along the coast of Japan, Proc. Japan Conf. on Coastal Eng., Vol.35, pp.232-236, 1988 (in Japanese).

5) Shimizu, K., Nagai, T., Satomi, S., Lee, J. H., Tomita, Y., Kudaka, M., Nukada, K.: Longterm Wave Climate Study Based on Meteorological and Observed Wave Data, Annual Journal of Coastal Eng., JSCE, Vol.53, pp.131-135, 2006 (in Japanese).

6) Seki, K., Kawai, H., Kawaguchi, K. and Satoh, M.: Long-term trend of wave characteristics on Japanese coast based on NOWPHAS data, Proc.of 22th international offshore and polar engineering conference, pp.685-692, 2012.

7) Yamaguchi, M., Ohfuku, M., Hatada, Y., Nonaka, H. and Emoto, K.: Analyses of year-to-year variation and trend for wave climatic parameters along the coasts of Japan using long-term measurement data, Proc. Coastal Eng., JSCE, Vol.54, pp.1296-1300, 2007 (in Japanese).

8) Mase, H., Tanaka, R., Mori, N., and Yasuda, T.: Long-term Variability of Annual Large Waves along Coasts of the Sea of Japan, Journal of Coastal Eng., JSCE, Vol.56, pp.1251-1255, 2009 (in Japanese). 